Cette dernière décennie a montré un nombre important de changements dans le traitement, l'outcome et la qualité de vie des personnes infectées par le virus VIH. Cela conduit inévitablement à des modifications de la représentation collective de la maladie et des dangers liés aux maladies sexuellement transmissibles. Il est par conséquent essentiel de refaire régulièrement et scientifiquement le point de la situation afin d'informer au mieux la population ainsi que les professionnels de la santé sur ces évolutions, ceci afin de ne pas contribuer à une banalisation de l'ensemble des maladies sexuellement transmissibles. Les présents textes orientent parfaitement le lecteur, c'est pourquoi nous vous en recommandons vivement la consultation.

Domaine Santé et prévention de la FMH

\title{
La prévention du sida devient plus simple, mais aussi plus complexe!
}

\section{Pietro Vernazza}

Président de la Commission fédérale pour les problèmes liés au sida CFS
«Sortez couverts.» Ce mot d'ordre est très clair. Tout comme le message actuel de la prévention contre le sida, à savoir, 1. pas de pénétration sans condom; 2. pas de sperme dans la bouche. Un concept percutant et efficace. Et qui fonctionne. La campagne suisse de prévention du sida autrefois Stop SIDA, aujourd'hui Love Life - a eu de grandes répercussions. Lorsque les mesures de prudence sont respectées, il est aujourd'hui possible d'éviter pratiquement dans chaque cas l'infection du virus VIH transmise par voie sexuelle. Que veut-on de plus simple?

Si la consigne est simple, elle n'est pas forcément facile à suivre. Certes, il est relativement aisé de respecter les règles du safer sex avec un partenaire occasionnel. En revanche, le condom est plutôt considéré comme un corps étranger dans le cadre du partenariat fixe. Pour les couples dont un partenaire est séropositif, l'utilisation régulière du condom a parfois des conséquences importantes et n'est pas le seul facteur à péjorer la vie sexuelle. La crainte d'une transmission du virus VIH au partenaire est constante chez la plupart des personnes concernées, malgré le condom. De nombreux couples aimeraient des enfants et doivent y renoncer sur la base de la recommandation du safer sex, ou se soumettre à des interventions désagréables et chères en médecine de la procréation sans garantie de succès. Malgré les problèmes posés par le safer sex, plus de $80 \%$ des couples dont un partenaire est séropositif en observent les règles et utilisent des condoms à chaque rapport sexuel pour ne pas courir le risque d'une transmission, comme le montrent les données de l'Etude suisse de cohorte VIH.
Quel est l'ordre de grandeur du risque couru? Que savent les couples à ce sujet? Il y a 15 ans déjà, une étude européenne réalisée auprès d'un certain nombre de couples avait évalué le risque de transmission du virus VIH. Le résultat obtenu était alors d'environ 1 sur 300 pour chaque rapport sexuel non protégé, soit une raison suffisante pour promouvoir le condom.

Et aujourd'hui? Le visage du sida a complètement changé au cours des dix dernières années en raison du traitement appliqué pour le virus VIH. Chez les personnes qui suivent une thérapie antirétrovirale de manière systématique, il n'est plus possible de détecter un virus actif dans le sang. Les infections opportunistes ont disparu et l'espérance de vie passe dans une fourchette «normale». Cette «normalisation» s'impose peu à peu aux personnes concernées mais aussi aux assureurs-vie, aux employeurs et autres.

Néanmoins, qu'en est-il du risque de transmission pendant une thérapie menée de façon optimale? Le virus disparaît des sécrétions sexuelles, mais pas la crainte d'une transmission sexuelle, raison pour laquelle la Commission d'experts Clinique et Thérapie VIH et sida (CCT) a étudié les bases scientifiques devant permettre d'évaluer le risque de transmission et le traitement. S'appuyant sur des données épidémiologiques et biologiques, la Commission est parvenue à la conclusion qu'une thérapie antivirale bien menée rend le risque à tel point négligeable qu'aucun cas de ce genre n'a été décrit à ce jour. Le risque théorique ainsi calculé figure parmi les risques normaux de la vie tels que, p. ex., un déplacement en avion. 
Quant aux couples dont un partenaire est séropositif, cette information leur simplifie grandement la vie. Qui recommanderait à quelqu'un de renoncer à un voyage en avion par crainte d'un crash? Lorsque les conditions sont optimales, un couple dont un partenaire est séropositif peut, aujourd'hui, avoir des rapports sexuels normaux sans condom. Aucune crainte de contaminer le partenaire. Plus de condom entravant le désir d'avoir un enfant. Par conditions optimales, on entend ce qui suit: une trithérapie stable, aucun virus détectable dans le sang, aucune maladie vénérienne. Lorsque ces conditions sont remplies, ce qui est le cas pour la majorité des personnes traitées, la prévention s'avère ainsi effectivement simple.

Le message à transmettre devient toutefois plus complexe: il doit être individualisé. La thérapie mais aussi la ou le partenaire séronégatif doivent être intégrés dans la prise en charge. La prévention des maladies vénériennes prend de l'importance. Les couples doivent être conseillés de manière plus approfondie. Et puis, après vingt années de slogan «Sortez couverts», il ne sera pas simple de relativiser la crainte d'une infection, profondément ancrée dans la tête des personnes concernées. Mais lorsque ce processus est engagé, les personnes infectées par le virus VIH voient leur qualité de vie s'améliorer. Il était temps!

Compte tenu de l'évaluation faite par la CCT, la Commission fédérale pour les problèmes liés au sida en a examiné l'importance pour la prévention. Les conclusions qui en résultent pour le conseil ont été résumées dans une brève information destinée aux services de consultation et au corps médical. M'exprimant au nom de la Commission, je vous recommande chaudement la lecture de ces recommandations. 